\title{
Size Control of Cobalt Oxide Nanoparticles and Its Effect on the Fenton Catalytic Activity
}

\author{
Elvera L. Viljoen*, Semakaleng V. Kganyago, Augustine E. Ofomaja \\ Vaal University of Technology, Private Bag x021 Vanderbijilpark,1900, South Africa
}

Received: 8 January 2020

Accepted: 5 April 2020

\begin{abstract}
Cobalt oxide nanoparticles were prepared using a precipitation-oxidation method at mild reaction conditions. The nanoparticles had spherical shapes and sizes that ranged from $4.6 \mathrm{~nm}$ to $19.4 \mathrm{~nm}$ as determined by TEM and XRD. XRD indicated that the nanoparticles consisted only of the $\mathrm{Co}_{3} \mathrm{O}_{4}$ phase. The nanoparticles' size was controlled using different amounts of the oxidant, hydrogen peroxide. The size was controlled in the absence of capping molecules. The yield increased with an increase in the amount of hydrogen peroxide used. The cobalt oxide nanoparticles were used as catalyst for the Fenton reaction to degrade methylene blue dye by hydrogen peroxide oxidation. The catalytic activity increased with a decrease in particle size. A percentage degradation of $99 \%$ in 30 minutes was obtained when the $4.6 \mathrm{~nm}$ sized nanoparticles was used as catalyst. No significant methylene blue degradation was observed in the absence of the catalyst.
\end{abstract}

Keywords: nanoparticles, Fenton, catalysis, water remediation, effect of size

\section{Introduction}

The pollution of the world's limited water resources is becoming an increasingly difficult challenge. Therefore, it is important to develop processes to remediate polluted water. Organic pollutants that are aromatic in nature are resistant to natural biodegradation mechanisms. These pollutants originate from chemical industries, pharmaceutical companies and pesticides used in agriculture. Advanced oxidation processes (AOP) can be used to degrade these recalcitrant organic pollutants through chemical oxidation. Examples

*e-mail: elverav@vut.ac.za of AOP are the Fenton reaction, ozonation, and photocatalysis. In this study methylene blue dye was used as a model aromatic organic pollutant.

The Fenton reaction is catalysed by transition metal oxides such as iron oxide, copper oxide and cobalt oxide. Heterogenous catalysts are preferred for commercial application to the originally used homogenous iron ions, due to the easier separation of heterogenous catalysts from the water.

Espinoza et al. [1] showed that smaller iron oxide nanoparticles supported on diamond are more active than larger particles for photo-Fenton catalysis. Dong et al. [2] tested unsupported cobalt oxide particles with sizes of $3.5 \mathrm{~nm}, 19 \mathrm{~nm}$ and $70 \mathrm{~nm}$ and showed that the rate of oxidation degradation of phenol by ozone increases with a decrease in the unsupported 
cobalt oxide particle size. Wan et al. [3] showed that the Fenton activity increased when unsupported iron oxide particles decreased from $600 \mathrm{~nm}$ to $30 \mathrm{~nm}$. This increase in activity with a decrease in the particle size may be explained by an increase in the surface area with a corresponding decrease in the particle size. From a catalysis point of view, the investigation of sizes smaller than $20 \mathrm{~nm}$ is of more interest and deviations due to the small size have been found for other reactions like Fischer-Tropsch. For example, Bezemer et al. [4] found that the Fischer-Tropsch catalytic activity increased when the size was decreased from $27 \mathrm{~nm}$ to $6 \mathrm{~nm}$ but the activity decreased on further reduction of the cobalt particle size to $2.6 \mathrm{~nm}$. This research indicated that there may be an optimum size to achieve the highest activity and that it thus is important to specifically test in the size range below $20 \mathrm{~nm}$. No research has been found specifically on the size effect of cobalt oxide on the Fenton reaction in this size range.

In this study, the effect of the size of unsupported cobalt oxide nanoparticles were investigated. Unsupported, non-agglomerated nanoparticles have been chosen to study the effect of size in the absence of mass transfer limitations and metal oxide support interactions. Commercial catalysts are typically supported since supported metal oxide nanoparticles are easier to separate and supported catalysts are required for fixed bed operation to minimise pressure drop over the reactor. Commercial supports often have pore sizes smaller than $20 \mathrm{~nm}$ to maximize the surface area of the support. This leads to the formation of metal oxide particle sizes smaller than $20 \mathrm{~nm}$ when the metal oxide particle form inside the support pores [5]. Therefore, this study focused on particles sizes smaller than $20 \mathrm{~nm}$ and to obtain more information specifically in this region of interest from a commercial application point of view.

The preparation of cobalt oxide with different sizes is also of interest for non-catalytic applications such as batteries, gas-sensing and data storage. Other properties, apart from catalytic activity, like the current density, capacitive performance [6] and magnetic properties [7] are also influenced by the cobalt oxide particle size. For example, small sized cobalt oxide nanoparticles are ferromagnetic and when the size is increased, they become superparamagnetic [7].

There are various bottom-up methods, such as precipitation, hydrothermal, solvothermal, vapour deposition, and thermal decomposition, to prepare nanoparticles [8, 9]. Each preparation method has unique advantages and disadvantages over the alternative methods $[8,9]$. The major disadvantage of hydrothermal and solvothermal is that a high pressure autoclave is required to heat the reaction mixture above the solvent boiling point $[8,9]$. The advantage the simple precipitation oxidation method is that cobalt oxide nanoparticles can be prepared at low temperatures $\left(<100^{\circ} \mathrm{C}\right)$ and atmospheric pressure thus simple glassware can be used. Solvothermal, physical and chemical vapor deposition and thermal decomposition of metal complexes methods require solvents, capping molecules, surfactants or metal complexes that can be expensive, toxic and explosive $[8,9]$ which can be avoided if a simple precipitation oxidation method is used.

The cobalt oxide nanoparticles in this study have been prepared using a precipitation oxidation method. $\mathrm{H}_{2} \mathrm{O}_{2}$ oxidation was used to form $\mathrm{Co}_{3} \mathrm{O}_{4}$ at low temperatures instead of the more usual calcination in air, in order to prevent sintering [10]. This method has been selected since large enough quantities of nanoparticles can be prepared which is required for catalytic testing. Capping molecules are often used for size and shape control of nanoparticles. In this study, the cobalt oxide nanoparticles were specifically prepared in the absence of complex organic capping molecules since capping molecules are expected to be adsorbed on the surface, leading to a decrease in the catalytic activity by blocking the catalytic sites. Previously it has been reported that the sizes of the nanoparticles can be controlled by using different amounts of hydrogen peroxide $[10,11]$. An increase in the molar ratio of $\mathrm{H}_{2} \mathrm{O}_{2}$ to $\mathrm{Co}^{2+}$ from 4:1 to 20:1 was reported to result in an increase in the $\mathrm{Co}_{3} \mathrm{O}_{4}$ nanoparticle size from about $18 \mathrm{~nm}$ to about $27 \mathrm{~nm}$ [10]. In contrast, the increase of the $\mathrm{H}_{2} \mathrm{O}_{2}$ to $\mathrm{Co}^{2+}$ molar ratio from 1:1 to $3: 1$ resulted in a decrease in the size of the obtained $\mathrm{Co}_{3} \mathrm{O}_{4}$ nanoparticles from $\sim 300 \mathrm{~nm}$ to $\sim 30 \mathrm{~nm}$ [11]. The effect of $\mathrm{H}_{2} \mathrm{O}_{2}$ may be related to the molar ratio of $\mathrm{H}_{2} \mathrm{O}_{2}$ to $\mathrm{Co}^{2+}$ as well as the preparation method used. It can be argued that at low $\mathrm{H}_{2} \mathrm{O}_{2}$ to $\mathrm{Co}^{2+}$ molar ratio the size decreases and at higher $\mathrm{H}_{2} \mathrm{O}_{2}$ to $\mathrm{Co}^{2+}$ molar ratio the size increases. No prior research has been found where the $\mathrm{H}_{2} \mathrm{O}_{2}$ amount has been used to control the cobalt oxide nanoparticle size in the range 5 to $20 \mathrm{~nm}$.

Theoretically, a molar ratio of $\mathrm{H}_{2} \mathrm{O}_{2}$ to $\mathrm{Co}^{2+}$ of $0.33: 1$ is required to form $\mathrm{Co}_{3} \mathrm{O}_{4}$. Research has shown that a much higher amount than the theoretical amount is required to form only $\mathrm{Co}_{3} \mathrm{O}_{4}$. Yang et al. [12] indicated that experimentally an excess of hydrogen peroxide is required $\left(\mathrm{H}_{2} \mathrm{O}_{2}\right.$ to $\mathrm{Co}^{2+}$ above 2.5:1.0), which they attributed to the decomposition of $\mathrm{H}_{2} \mathrm{O}_{2}$. Amiri et al. [10] utilized a much larger excess of hydrogen peroxide with a molar ratio of $\mathrm{H}_{2} \mathrm{O}_{2}$ to $\mathrm{Co}^{2+}$ of 20:1 (assuming a $\mathrm{H}_{2} \mathrm{O}_{2}$ concentration of $30 \%$ ). An increase in the excess of oxidant added to the synthesis mixture resulted in a decrease in cobalt hydroxide and increasing the yield of $\mathrm{Co}_{3} \mathrm{O}_{4}$ nano-particles [12]. A high reaction temperature of $150^{\circ} \mathrm{C}$ or higher is also required to minimize the amount of cobalt hydroxide like species and to form only $\mathrm{Co}_{3} \mathrm{O}_{4}[13,14]$. In this study a low molar ratio of $\mathrm{H}_{2} \mathrm{O}_{2}$ to $\mathrm{Co}^{2+}$ at a relatively low temperature was used which is expected to result in a mixture of cobalt hydroxide, cobalt hydroxide nitrate species and $\mathrm{Co}_{3} \mathrm{O}_{4}$. A purification step is thus required to remove these species. Pure $\mathrm{Co}_{3} \mathrm{O}_{4}$ can be obtained from these solid mixtures by suspending the solid in dilute hydrochloric 
acid solutions resulting in the selective dissolution of these hydroxide species [15].

The objective of this study was to develop a simple low temperature, atmospheric pressure, nanoparticles preparation method without capping molecules using $\mathrm{H}_{2} \mathrm{O}_{2}$ to control the size between 5 and $20 \mathrm{~nm}$ and to obtain a high yield of pure $\mathrm{Co}_{3} \mathrm{O}_{4}$. These nanoparticles were subsequently used to study the influence of cobalt oxide nanoparticle size on the Fenton catalytic activity.

\section{Materials and Methods}

\section{Materials}

Cobalt nitrate hexahydrate, $\left(\mathrm{Co}\left(\mathrm{NO}_{3}\right)_{2} \cdot 6 \mathrm{H}_{2} \mathrm{O}\right.$, $(98 \%)$, and sodium hydroxide, $(\mathrm{NaOH}, 98 \%)$ were purchased from Sigma-Aldrich. Hydrogen peroxide $\left(\mathrm{H}_{2} \mathrm{O}_{2}\right.$ in water, 30\%), hydrochloric acid, $(\mathrm{HCl} \mathrm{32 \% )}$ and methanol, $\left(\mathrm{CH}_{3} \mathrm{OH}, 99 \%\right)$ were purchased from Glassworld. Butanol, $\left(\mathrm{C}_{4} \mathrm{H}_{10} \mathrm{O}, 99.8 \%\right)$ was obtained from Laboratory Consumables. All chemicals were used as received, without further purification.

\section{Preparation of $\mathrm{Co}_{3} \mathrm{O}_{4}$ Nanoparticles}

Cobalt nitrate hexahydrate (5.8178 g) was dissolved in $10 \mathrm{~mL}$ of distilled water and a solution of hydrogen peroxide $(2.9 \mathrm{mmol})$ dissolved in $10 \mathrm{~mL}$ of distilled water were mixed together at room temperature. Sodium hydroxide (1.2743 g) was dissolved in $100 \mathrm{~mL}$ of distilled water. The mixture of cobalt nitrate/hydrogen peroxide and n-butanol $(20 \mathrm{~mL})$ were added to the solution of sodium hydroxide; the mixture turned brown/black. The solution contained in a round bottom flask was placed in an unheated heating mantle and heated up to $85^{\circ} \mathrm{C}$. The mixture was kept at $85^{\circ} \mathrm{C}$ for 16 hours while continuously bubbling air and stirring with a magnetic stirrer at $300 \mathrm{rpm}$. The solution was allowed to cool to room temperature and centrifuged at $5000 \mathrm{rpm}$ for 5 minutes. The solid product was washed three times with $50 \mathrm{~mL} 2 \mathrm{M} \mathrm{HCl}$ aliquots to dissolve the unreacted cobalt hydroxide, twice with $50 \mathrm{~mL}$ of distilled water to remove the $\mathrm{HCl}$ and finally, once with $50 \mathrm{~mL}$ of methanol to remove water. The nanoparticles produced were left to dry in an oven at $120^{\circ} \mathrm{C}$ overnight. The same procedure was followed subsequently, by only changing the amount of hydrogen peroxide used (2.9, 1.4, 0.74, 0.37, 0.14 mmol $\mathrm{H}_{2} \mathrm{O}_{2}$ ).

\section{Characterization}

XRD analyses were done using the ShimadzuXRD 700, X-Ray Diffractometer with $\mathrm{Cu}$ Ka radiation $(\lambda=1.154056 \AA)$. A scan speed of $1 \%$ minute, current of $30 \mathrm{~mA}$ and a voltage of $40 \mathrm{kV}$ were used. The FWHM (Full-Width Half-Maximum) was determined by fitting a Gaussian peak using the Fityk ${ }^{\mathrm{TM}}$ peak fitting programme. The FWHM was used to calculate the average crystallite size using the Scherrer equation as shown in Equation 1.

$$
\mathrm{D}=\mathrm{K} \lambda / \beta \cos \theta
$$

A value of 0.9 was used for the Scherrer constant $\mathrm{K}, 1.154056 \AA$ for $\lambda, \beta$ is the line width FWHM as $2 \theta, \theta$ is the Bragg angle, and D is the crystallite size. The strongest diffraction peak, (311), at $\sim 36^{\circ} 2 \theta$ were used to calculate the average crystallite size. UV-VIS spectroscopy analyses were performed with a double beam spectrometer - a Perkin Elmer Lambda 25 UV-VIS spectrometer, with a tungsten and deuterium lamp, using a bandwidth of $1 \mathrm{~nm}$ with a fixed slit. A baseline setting was conducted by using pure water as a reference sample. A very small amount of the solid sample/crystals was dispersed in water. A Gaussian peak was fitted to the adsorption peak with the program Fityk $^{\mathrm{TM}}$ to obtain the peak maximum position. The size and shape of the dried unsupported nanoparticles were determined using a TEM, LEO TEM 912, with an acceleration voltage of $120 \mathrm{~kW}$ and a tungsten wire filament. The nanoparticles dispersed in the methanol were pipetted onto carbon coated, copper grids and allowed to dry. The nanoparticles' sizes were measured using the software programme; Image ${ }^{\mathrm{TM}}$.

\section{Fenton Degradation Tests}

Reactions were carried out in a $250 \mathrm{~mL}$ beaker covered with aluminium foil to avoid photo-degradation. A volume of $10 \mathrm{~mL}$ of methylene blue stock solution (1000 ppm) and $20 \mathrm{~mL}$ of distilled water were mixed. A mass of $0.01 \mathrm{~g}$ of catalyst was dispersed in $50 \mathrm{~mL}$ of distilled water and sonicated for 30 minutes using an ultrasonic bath. The catalyst was added to the solution of methylene blue. The mixture was stirred for 1 hour in order reach adsorption equilibrium of the methylene blue on the catalyst surface. The Fenton reaction is initiated with the addition of $20 \mathrm{~mL}$ of $30 \% \mathrm{H}_{2} \mathrm{O}_{2}$. Small-sized samples $(1 \mathrm{~mL})$ were taken periodically. Isopropanol $(1 \mathrm{~mL})$ was added to the sample to stop the reaction by quenching the $\mathrm{OH}$ radicals. Then the solution was diluted to the mark with cold distilled water in $100 \mathrm{~mL}$ volumetric flask. The sample solution was centrifuged to remove the solid catalyst particles from the liquid phase. The concentration of methylene blue was determined with UV-VIS spectroscopy at a wavelength of $660 \mathrm{~nm}$.

\section{Results and Discussion}

\section{Catalyst Characterization}

X-ray Diffraction (XRD) results showed that the cubic phase $\mathrm{Co}_{3} \mathrm{O}_{4}$ (JCPDS data, PDF card No.00-04-1003) was obtained for all the samples. No other diffraction peaks were observed in the XRD 


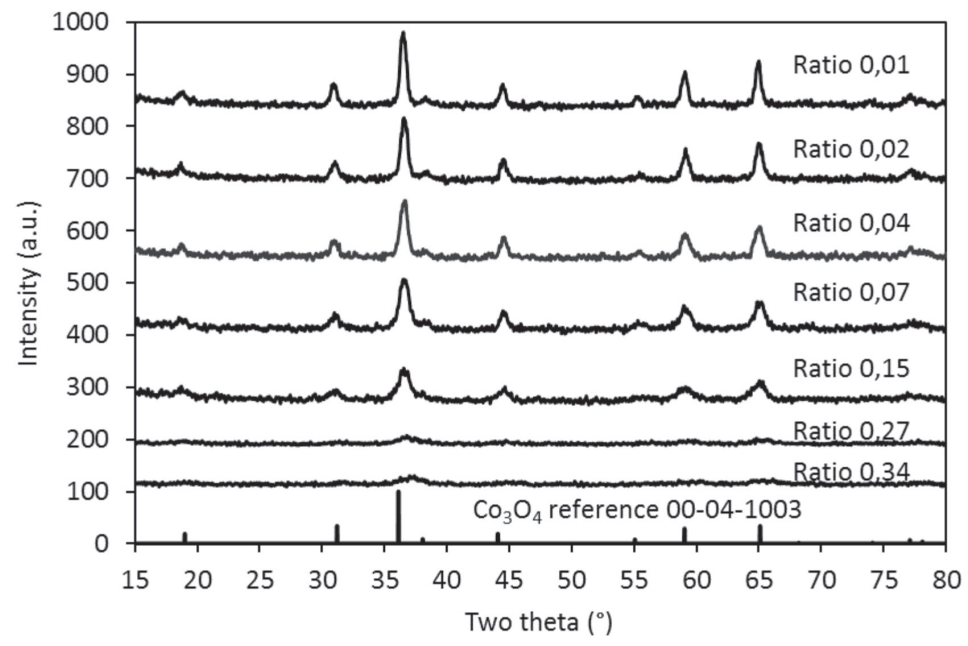

Fig. 1. X-ray Diffraction pattern of the $\mathrm{Co}_{3} \mathrm{O}_{4}$ nanoparticles prepared at $85^{\circ} \mathrm{C}$ for $16 \mathrm{hrs}$.

spectra such as cobalt hydroxide indicating that the purification technique with diluted hydrochloric acid dissolved the cobalt hydroxide-like species. The diffraction peaks became broader with an increase in the $\mathrm{H}_{2} \mathrm{O}_{2}$ to $\mathrm{Co}^{2+}$ mol ratio indicating that the cobalt
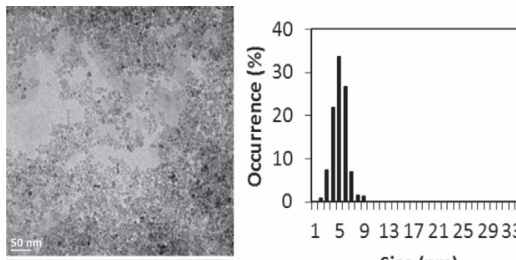

$\mathrm{H}_{2} \mathrm{O}_{2}: \mathrm{CO}^{2+}$ ratio: 0.15 Average: $4.6 \mathrm{~nm}$

Standard deviation: $1.2 \mathrm{~nm}$
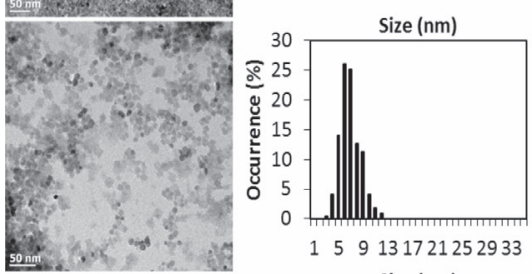

$\mathrm{H}_{2} \mathrm{O}_{2}: \mathrm{CO}^{2+}$ ratio: 0.07

Average: $6.4 \mathrm{~nm}$

Standard deviation: $1.6 \mathrm{~nm}$
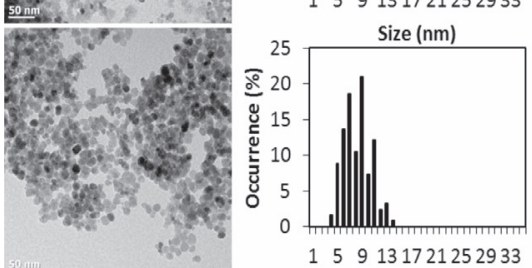

$\mathrm{H}_{2} \mathrm{O}_{2}: \mathrm{Co}^{2+}$ ratio: 0.04 Average: $7.7 \mathrm{~nm}$ Standard deviation: $2.2 \mathrm{~nm}$
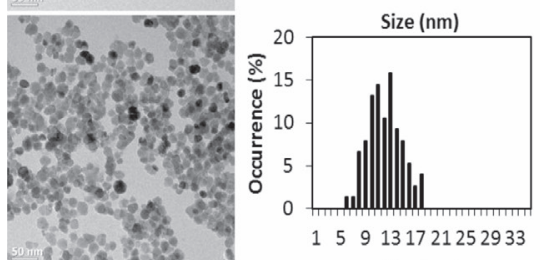

$\mathrm{H}_{2} \mathrm{O}_{2}: \mathrm{CO}^{2+}$ ratio: 0.02 Average: $11.6 \mathrm{~nm}$ Standard deviation: $2.7 \mathrm{~nm}$
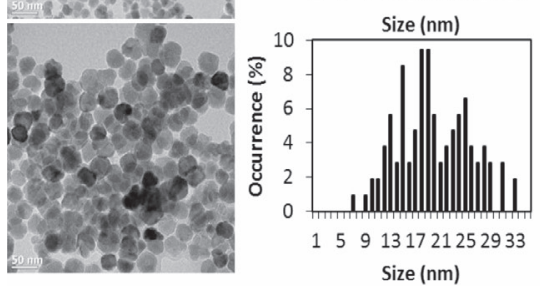

$\mathrm{H}_{2} \mathrm{O}_{2}: \mathrm{Co}^{2+}$ ratio: 0.01 Average: $19.4 \mathrm{~nm}$ Standard deviation: $5.7 \mathrm{~nm}$

Fig. 2. TEM analyses of $\mathrm{Co}_{3} \mathrm{O}_{4}$ nanoparticles. oxide crystallite size decreased with an increase in the $\mathrm{H}_{2} \mathrm{O}_{2}$ to $\mathrm{Co}^{2+}$ molar ratio (see Fig. 1). The size of the cobalt oxide crystallites was calculated using the Scherrer equation (see Fig. 3) which indicated that the crystallite size decreased from $14 \mathrm{~nm}$ to about $5 \mathrm{~nm}$ when the $\mathrm{H}_{2} \mathrm{O}_{2}$ to $\mathrm{Co}^{2+}$ molar ratio increased from 0.01 to 0.34 . TEM analyses indicated a similar trend to the XRD analyses and showed that an increase in the $\mathrm{H}_{2} \mathrm{O}_{2}$ to $\mathrm{Co}^{2+}$ molar ratio decreased the corresponding sizes of the $\mathrm{Co}_{3} \mathrm{O}_{4}$ nanoparticles (see Figs 2 and 3). This may be explained by the formation of more $\mathrm{Co}_{3} \mathrm{O}_{4}$ nuclei due to faster oxidation by the higher concentrations of $\mathrm{H}_{2} \mathrm{O}_{2}$. The particle size distribution (standard deviation) also decreased with an increase in the $\mathrm{H}_{2} \mathrm{O}_{2}$ to $\mathrm{Co}^{2+}$ molar ratio. The yield of the $\mathrm{Co}_{3} \mathrm{O}_{4}$ nanoparticles increased with an increase in the $\mathrm{H}_{2} \mathrm{O}_{2}$ amount (see Fig. 3) which is in agreement with literature [12]. The higher yield may be explained by a higher conversion of cobalt hydroxide to $\mathrm{Co}_{3} \mathrm{O}_{4}$ by oxolation which is a condensation type of reaction resulting in the formation of oxo bridges as shown in Equation 2 and 3 [12, 16, 17].

$$
\begin{array}{r}
\mathrm{Co}(\mathrm{OH})_{2}+\mathrm{H}_{2} \mathrm{O}_{2} \rightarrow \mathrm{Co}_{3} \mathrm{O}_{4}+4 \mathrm{H}_{2} \mathrm{O} \\
\text { particle-Co-O-H }+\mathrm{H}-\mathrm{O}-\mathrm{Co}-\text { particle } \\
\rightarrow \text { particle-Co-O-Co-particle }+\mathrm{H}_{2} \mathrm{O}
\end{array}
$$

The size of the smaller particles calculated using XRD results were found to be slightly larger than those obtained from TEM (see Table 2 and Fig. 4) and this slight difference might be due to the presence of a few larger nanoparticles that were not seen in the TEM images. The larger particles' XRD sizes were smaller than the size determined by TEM which may be explained by the particles containing some faults and cracks which is visible in some of the particles as seen in the TEM photographs.

TEM analysis showed that $\mathrm{Co}_{3} \mathrm{O}_{4}$ nanoparticles have mostly spherical shapes (see Fig. 3) for a $\mathrm{H}_{2} \mathrm{O}_{2}$ to $\mathrm{Co}^{2+}$ 


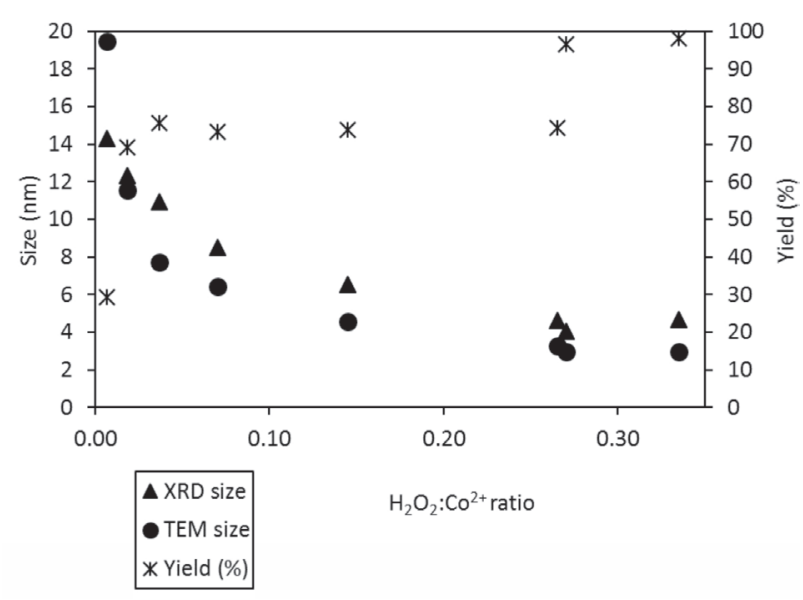

Fig. 3. Effect of the $\mathrm{H}_{2} \mathrm{O}_{2}: \mathrm{Co}^{2+}$ molar ratio on the $\mathrm{Co}_{3} \mathrm{O}_{4}$ yield and nanoparticles sizes as determined by TEM and XRD.

molar ratio between 0.02 and 0.15 . More particles with sharp edges were observed when the $\mathrm{H}_{2} \mathrm{O}_{2}$ to $\mathrm{Co}^{2+}$ molar ratio was decreased. The shape may be changing from spherical to hexagonal or cubic. The rate of conversion of the cobalt hydroxide to the $\mathrm{Co}_{3} \mathrm{O}_{4}$ phase may have been slower at the lower $\mathrm{H}_{2} \mathrm{O}_{2}$ : $\mathrm{Co}^{2+}$ molar ratio resulting in thermodynamically controlled growth [18] rather than kinetically controlled growth of the cobalt oxide crystallites. Thermodynamically controlled growth will lead to the formation of thermodynamically more stable surfaces such as the $\{100\}$ crystal facet which has the lowest surface energy for the $\mathrm{Co}_{3} \mathrm{O}_{4}$ phase [19]. The $\{100\}$ crystal facets will lead to a cubic shaped nanoparticle.

At a $\mathrm{H}_{2} \mathrm{O}_{2}$ to $\mathrm{Co}^{2+}$ molar ratios of 0.27 and 0.34 , the TEM analyses showed that the nanoparticles were agglomerated and not well defined and the XRD diffraction peaks were broad indicating that the crystallites are small and amorphous. The reported sizes in Fig. 3 for the nanoparticles prepared at $\mathrm{H}_{2} \mathrm{O}_{2}$ to $\mathrm{Co}^{2+}$ molar ratios of 0.27 and 0.34 , are rough estimates.

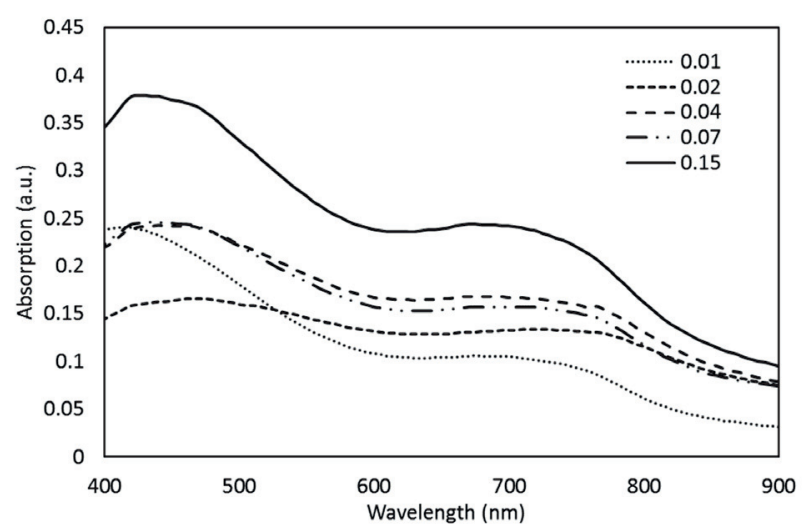

Fig. 4. UV-VIS spectra of the cobalt oxide nanoparticles suspended in water.
The optical properties were investigated by UV-VIS spectroscopy as shown in Fig. 4. The two absorption peaks observed at wavelength around $750 \mathrm{~nm}$ and $450 \mathrm{~nm}$ (see Fig. 4) are assigned to ligand to metal charge transfers of $\mathrm{O}^{2-} \rightarrow \mathrm{Co}^{3+}$ and $\mathrm{O}^{2-} \rightarrow \mathrm{Co}^{2+}$ since the $\mathrm{Co}_{3} \mathrm{O}_{4}$ phase contains two cobalt ion oxidation states, $\mathrm{Co}(\mathrm{II})$ and $\mathrm{Co}(\mathrm{III})$ [20]. The wavelength of the peak maximum of the $\mathrm{Co}_{3} \mathrm{O}_{4}$ nanoparticles increased when the particle size increased from $4.6 \mathrm{~nm}$ to $11.6 \mathrm{~nm}$ as shown in Fig. 5. This indicates that the band gap increased with a decrease in the particle size from $4.6 \mathrm{~nm}$ to $11.6 \mathrm{~nm}$, which is in line with that reported in literature [20-22] The band gap of the $19.4 \mathrm{~nm}$ particles was similar to the $4.6 \mathrm{~nm}$ particles (see Fig. 5). Not only the nanoparticles' size, but also their shape has an influence on the optical properties of metal oxides [21]. The TEM of the $19.4 \mathrm{~nm}$ particles shows that they are not spherical, but with flat edges and cracks. This shape change may explain the lower wavelength of the peak maxima obtained for the $19.4 \mathrm{~nm}$ particles.

$\mathrm{Co}_{3} \mathrm{O}_{4}$ can also be used as a photocatalyst for the degradation of organic pollutants [23, 7]. The catalytic activity of a photocatalyst is influence by the band gap of photocatalyst and surface area which is related to the particle size $[23,7]$. The optical properties become an imported characteristic when the catalyst is used as a photocatalysis instead of Fenton catalysis since photocatalysis requires the excitation of an electron from the valance band to the conduction band by the adsorption of light [7, 24, 25]. Adsoprtion in visible light and a small band gap is preferred because solar light consist mostly of visible light. The blue shift of the adsorption peak due to a decrease in the cobalt nanoparticles size as shown in Fig. 4, indicating an increase in the band gap, may possibly decrease the visible light photocatalytic activity even though the catalytic surface area has increased.

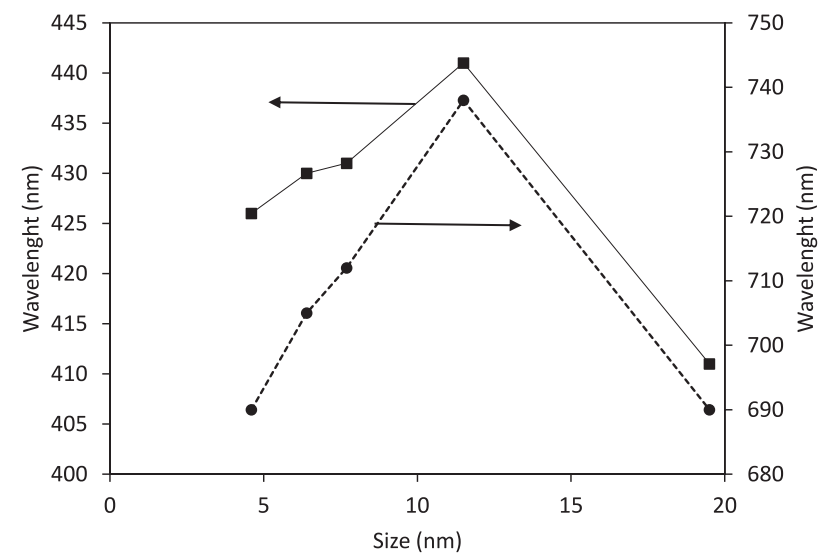

Fig. 5. Influence of the cobalt nanoparticle size on the peak maximum wavelengths. 

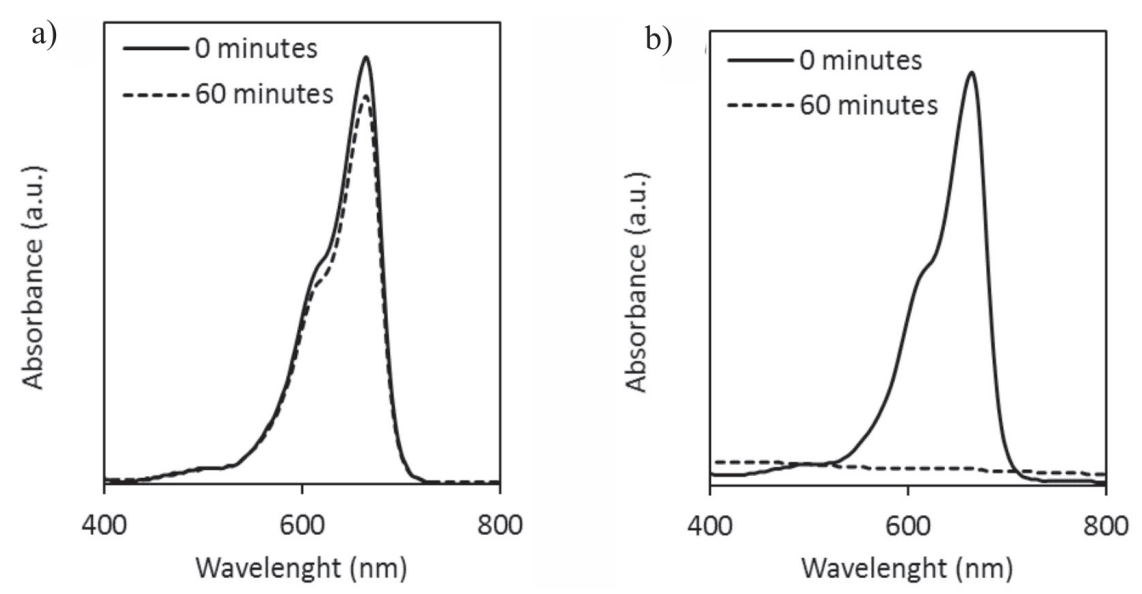

Fig. 6. Degradation of methylene blue a) without and b) with $\mathrm{Co}_{3} \mathrm{O}_{4}$ nanoparticles.

\section{Catalytic Activity of $\mathrm{Co}_{3} \mathrm{O}_{4}$ Nanoparticles on the Degradation of Methylene Blue Dye}

The ability of $\mathrm{H}_{2} \mathrm{O}_{2}$ to degrade methylene blue in the absence of a catalyst was evaluated as shown in Fig. 6a). The intense absorption peak at $660 \mathrm{~nm}$ was still observed even after 60 min reaction which means that a negligible amount of degradation of methylene blue took place which may be explained by the low oxidation potential of $\mathrm{H}_{2} \mathrm{O}_{2}$ compared with $\mathrm{OH}$ radicals. The addition of the catalyst resulted in the degradation of the methylene blue (Fig. 6b) which indicates that the catalyst is thus required to produce $\mathrm{OH}$ radicals by the Fenton reactions as shown in Equation 4.

$$
\mathrm{Co}^{2+}+\mathrm{H}_{2} \mathrm{O}_{2} \rightarrow \mathrm{Co}^{3+}+\bullet \mathrm{OH}+\mathrm{OH}^{-}
$$

An induction time of about 10 minutes was observed as shown in Fig. 7. Induction periods have also been observed for other Fenton catalytic systems $[26,27]$ and have been explained by a time-dependent activation process by dissolution of the metal ions or the protonation of the surface species since lowering the $\mathrm{pH}$ decreases the induction period.

The rate of catalytical degradation of methylene blue increase with a decrease in the $\mathrm{Co}_{3} \mathrm{O}_{4}$ nanoparticle sizes as depicted in Fig. 7a). The degradation reaction was first order in methylene blue as shown in Fig. 7b). This observation agrees with previous research for the Fenton and ozonation oxidation degradation reactions $[1,2,3]$. However, an optimum size was not observed for the Fenton reaction as reported for the FischerTropsch reaction [4], which indicates that when preparing a commercial supported catalyst one can aim to make a catalyst with the smallest crystallite size. The metal support interaction, which is typically present for very small metal oxide nanoparticles, will not influence the catalytic activity. Strong metal support interaction may influence the reducibility of the metal oxide and may decrease the rate of reduction of the $\mathrm{Co}^{3+}$ back to $\mathrm{Co}^{2+}$ as shown in Equation 5. The influence of the support needs to be considered when preparing supported catalysts.

$$
\mathrm{Co}^{3+}+\mathrm{H}_{2} \mathrm{O}_{2} \rightarrow \mathrm{Co}^{2+}+\mathrm{HOO} \bullet+\mathrm{H}^{+}
$$

The advantage of using a support is that it prevents the nanoparticles from agglomerating since not only the size but also on the amount of agglomeration affects the activity [28]. The use of mezoporous silica as support increased the activity of $\mathrm{Co}_{3} \mathrm{O}_{4}$ nanoparticles which had a size of $23 \mathrm{~nm}$ [29].
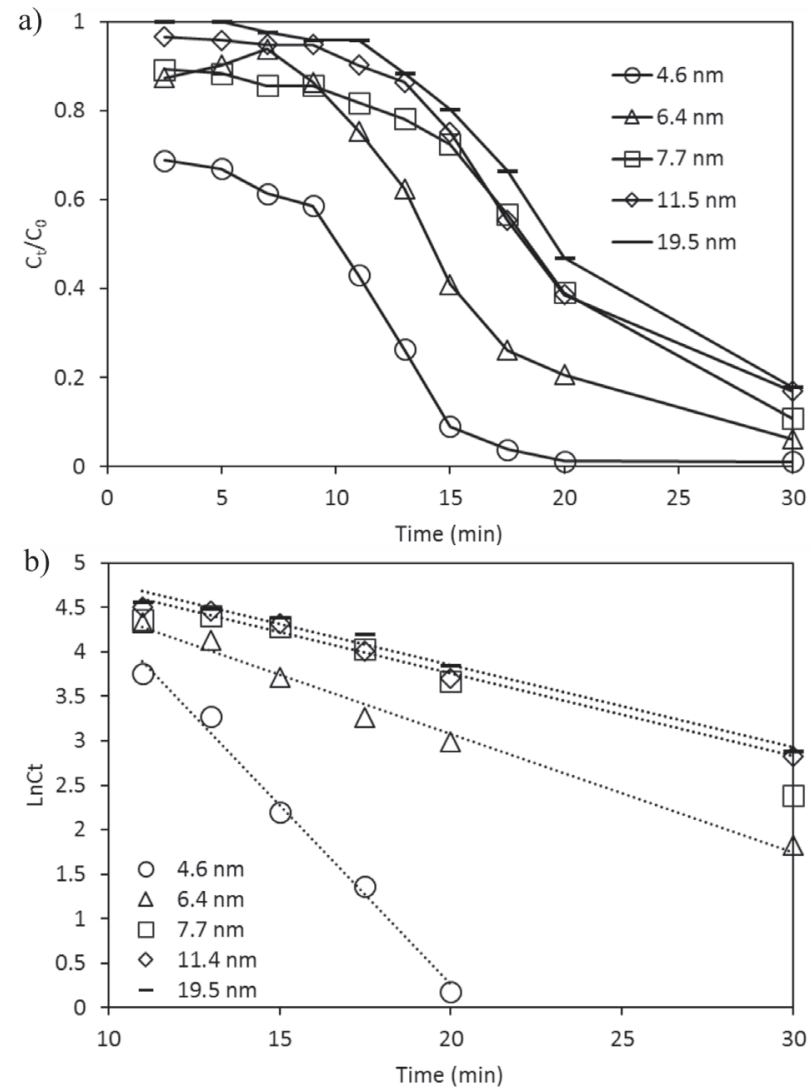

Fig. 7. Methylene blue degradation using cobalt oxide nanoparticles with different sizes as catalysts. 
In would be interesting to test the effect of the $\mathrm{Co}_{3} \mathrm{O}_{4}$ crystallite size on the photocatalytic activity since an increase in the rate constant was observed for an increase in the crystallite size of $\mathrm{CoFe}_{2} \mathrm{O}_{4}$ from $13.4 \mathrm{~nm}$ to $29.1 \mathrm{~nm}$ [22] which is in contrast to the finding is this study which may be explained by the photocatalysis activity being influenced by both the band gap and the surface area where as the Fenton catalysis only depends on the surface area. Both the band gap and the surface area are influenced by the size of the nanoparticles.

\section{Conclusions}

A facile precipitation-oxidation method was developed to prepare $\mathrm{Co}_{3} \mathrm{O}_{4}$ nanoparticles of different sizes at atmospheric pressure and low temperature, without the use of complex organic capping agents. The size of $\mathrm{Co}_{3} \mathrm{O}_{4}$ nanoparticles was controlled by different amounts of $\mathrm{H}_{2} \mathrm{O}_{2}$ and a decrease in particle size was observed with an increase in the amount of $\mathrm{H}_{2} \mathrm{O}_{2}$ added. An insignificant amount of degradation took place in the absence of the $\mathrm{Co}_{3} \mathrm{O}_{4}$ nanoparticles indication the necessity of a catalyst in order for the Fenton reaction to proceed. The catalytic activity of the $\mathrm{Co}_{3} \mathrm{O}_{4}$ nanoparticles increased with a decrease in size from 19.5 to $4.6 \mathrm{~nm}$. A percentage degradation of $99 \%$ in 30 minutes was obtained when the $\mathrm{Co}_{3} \mathrm{O}_{4}$ nanoparticles of $4.6 \mathrm{~nm}$ was used as catalyst. The enhanced catalytic activity from the smallest nanoparticles may be explained in that the nanoparticles with smaller sizes have a higher surface area yielding more catalytically active sites. The results suggest that when preparing commercial catalysts, one should aim for the smallest possible metal oxide particle sizes to optimize the Fenton catalytic activity.

\section{Acknowledgements}

This work was based on the research supported by the National Research Foundation of South Africa from the grant, Unique Grant No. 99330, with additional funding from the Sasol University Collaboration Program and from the Vaal University of Technology. The authors express their thanks and appreciation to these institutions.

\section{Conflict of Interest}

The authors declare no conflict of interest.

\section{References}

1. ESPINOSA J.C., CATALÁ C., NAVALÓN S., FERRER B., ÁlVARO M., GARCÍA H. Iron oxide nanoparticles supported on diamond nanoparticles as efficient and stable catalyst for the visible light assisted Fenton reaction. Appl. Catal. B: Environmental. 226, 242, 2018.

2. DONG Y., HE K., YIN L., ZHANG A. A facile route to controlled synthesis of $\mathrm{Co}_{3} \mathrm{O}_{4}$ nanoparticles and their environmental catalytic properties. Nanotechnology. 18 (43), 435602, 2007.

3. WAN D., LI W., WANG G., WEI X. Size-controllable synthesis of $\mathrm{Fe}_{3} \mathrm{O}_{4}$ nanoparticles through oxidationprecipitation method as heterogeneous Fenton catalyst. J. Mater. Res. 31 (17), 2608, 2016.

4. BEZEMER G.L., BITTER J.H., KUIPERS H.P.C.E., OOSTERBEEK H., HOLEWIJN J.E., XU X., KAPTEIJN F., VAN DIILEN A., JONG K.P. Cobalt Particle Size Effects in the Fischer - Tropsch Reaction Studied with Carbon Nanofiber Supported Catalysts. J. Am. Chem. Soc. 128 (6), 3956, 2006.

5. CHENG K., VIRGINIE M., ORDOMSKY V.V, CORDIER C., CHERNAVSKII P.A., IVANTSOV M.I., PAUL S., WANG Y., KHODAKOV A.Y. Pore size effects in hightemperature Fischer - Tropsch synthesis over supported iron catalysts. J Catal. 328, 139, 2015.

6. ZHOU F., LIU Q., GU J., ZHANG W., ZHANG D. A facile low-temperature synthesis of highly distributed and sizetunable cobalt oxide nanoparticles anchored on activated carbon for supercapacitors. J. Power Sources. 273, 945, 2015.

7. PARHIZKAR J., HABIBI M.H. Investigation and Comparison of Cobalt ferrite composite nanoparticles with individual iron oxide and cobalt oxide nanoparticles in azo dyes removal, J. Water Environ. Nanotechnol. 4 (1), 17, 2019.

8. NIKAM A.V., PRASAD B.L.V., KULKARNI A.A. Wet chemical synthesis of metal oxide nanoparticles: A review. CrystEngComm. 20 (35), 5091, 2018.

9. JAMKHANDE P.G., GHULE N.W., BAMER A.H., KALASKAR M.G. Metal nanoparticles synthesis: An overview on methods of preparation, advantages and disadvantages, and applications. J Drug Deliv Sci Technol. 53, 101174, 2019.

10. HASHEMI AMIRI S.E., VAEZI M.R., ESMAIELZADEH KANDJANI A. A comparison between hydrothermally prepared $\mathrm{Co}_{3} \mathrm{O}_{4}$ via $\mathrm{H}_{2} \mathrm{O}_{2}$ assisted and calcination methods. J. Ceram. Process. Res. 12 (3), 327, 2011.

11. SONG X.C., WANG X., ZHENG Y.F., MA R., YIN H.Y. Synthesis and electrocatalytic activities of $\mathrm{Co}_{3} \mathrm{O}_{4}$ nanocubes. J Nanopart Res. 13 (3), 1319, 2011.

12. YANG Y. PING, HUANG K. LONG, LIU R. SHENG, WANG L. PING, ZENG W. WEN, ZHANG P. MIN. Shape-controlled synthesis of nanocubic $\mathrm{Co}_{3} \mathrm{O}_{4}$ by hydrothermal oxidation method. Transactions of Nonferrous Metals Society of China (English Edition). 17 (5), 1082, 2007.

13. JIANG Y., WU Y., XIE B., XIE Y., QIAN Y. Moderate temperature synthesis of nanocrystalline $\mathrm{Co}_{3} \mathrm{O}_{4}$ via gel hydrothermal oxidation. Mater. Chem. Phys. 74 (2), 234, 2002.

14. ZHANG Y., LIU Y., FU S., GUO F., QIAN Y. Morphologycontrolled synthesis of $\mathrm{Co}_{3} \mathrm{O}_{4}$ crystals by soft chemical method. Mater. Chem. Phys. 104 (1), 166, 2007.

15. FENG J., ZENG H.C. Size-Controlled Growth of $\mathrm{Co}_{3} \mathrm{O}_{4}$ Nanocubes. Chem. Mater. 15 (14), 2829, 2003.

16. BAUMGARTNER J., DEY A., BOMANS P.H.H., LE COADOU C., FRATZL P., SOMMERDIJK N.A.J.M., FAIVRE D. Nucleation and growth of magnetite from solution. Nat. Mater. 12 (4), 310, 2013. 
17. JOLIVET J.P., TRONC E., CHANÉAC C. Iron oxides: From molecular clusters to solid. A nice example of chemical versatility. Comptes Rendus - Geoscience. 338 (6-7), 488, 2006.

18. HE T., CHEN D., JIAO X., WANG Y., DUAN Y. Solubility-Controlled Synthesis of High-Quality $\mathrm{Co}_{3} \mathrm{O}_{4}$ Nanocrystals. Chem. Mater. 17, 4023, 2005.

19. SU W., DOU S., WANG G. Single Crystalline $\mathrm{Co}_{3} \mathrm{O}_{4}$ Nanocrystals Exposed with Different Crystal Planes for Li-O, Batteries. Scientic Reports. 4, 5767, 2014.

20. SARFRAZ A.K., HASANAIN S.K. Size dependence of magnetic and optical properties of $\mathrm{Co}_{3} \mathrm{O}_{4}$ nanoparticles. Acta Physica Polonica A. 125 (1), 139, 2014.

21. SINGH M., GOYAL M., DEVLAL K. Size and shape effects on the band gap of semiconductor compound nanomaterials. J. Taibah Univ. Sci. 12 (4), 470, 2018.

22. ANNIE VINOSHA P., JEROME DAS S. Investigation on the role of $\mathrm{pH}$ for the structural, optical and magnetic properties of cobalt ferrite nanoparticles and its effect on the photo-fenton activity. Materials Today: Proceedings. $\mathbf{5}$ (2), 8662, 2018.

23. EDLA R., PATEL N., EL KOURA Z., FERNANDES R., BAZZANELla N., MIOTELlO A. Pulsed laser deposition of $\mathrm{Co}_{3} \mathrm{O}_{4}$ nanocatalysts for dye degradation and CO oxidation. Appl. Surf. Sci. 302, 105, 2014.

24. MORIDON S.N.F., SALEHMIN M.I., MOHAMED M.A., ARIFIN K., MINGGU L.J., KASSIM M.B. Cobalt oxide as photocatalyst for water splitting: Temperature- dependent phase structures. Int. J. Hydrog. Energy. 44 (47), 25495, 2019.

25. MAGDALANE C.M., KAVIYARASU K., ARULARASU M.V., KANIMOZHI K., RAMALINGAM G. Structural and morphological properties of $\mathrm{Co}_{3} \mathrm{O}_{4}$ nanostructures: Investigation of low temperature oxidation for photocatalytic application for waste water treatment. Surf. Interfaces. 17, 100369, 2019.

26. ZHOU S., HU X., XU R., XIA C., ZHANG H., ZHANG C., WANG Y., SONG Z. Catalytic wet peroxide oxidation of 4-chlorophenol over Al-Fe-, Al-Cu-, and Al-Fe-Cupillared clays: Sensitivity, kinetics and mechanism. Appl Clay Sci. 95, 275, 2014.

27. XU L., WANG J. A heterogeneous Fenton-like system with nanoparticulate zero-valent iron for removal of 4-chloro-3methyl phenol. J. Hazard. Mater. 186 (1), 256, 2011.

28. VILJOEN E.L., THABEDE P.M., MOLOTO M.J., MUBIAYI K.P., DIKIZA B.W., AFRICA S. The influece of sodium hydroxide cencentration on the phase, morphology and agglomeration of cobalt oxide nanoparticles and application as Fenton catalyst. Dig. J. Nanomater. Biostructures. 14 (4), 1131, 2019.

29. DENG J., FENG S.F., ZHANG K., LI J., WANG H., ZHANG T., MA X. Heterogeneous activation of peroxymonosulfate using ordered mesoporous $\mathrm{Co}_{3} \mathrm{O}_{4}$ for the degradation of chloramphenicol at neutral $\mathrm{pH}$. Chem. Eng. J. 308, 505, 2017. 